\title{
Decision Support Opportunities in the Green Supply Chain Coordination
}

\author{
Gabriella Metszosy \\ University of Miskolc, 3515 Miskolc-Egyetemváros, Magyarország
}

Tamás Faludi

University of Miskolc, Faculty of Economics

\section{Abstract}

In the $21^{\text {st }}$ century, major changes have taken place in supply chain management. First of all, some new type of supply chains has appeared beside the traditional supply chains. The growing level of pollution, the decreasing level of non-renewable sources indicate changes in the business life. Companies find some alternate solutions to protect the environment - use renewable sources, integrate recycling processes, use the inverse logistics etc. So companies are getting to be eco-conscious, we are called them as 'green companies'. If these green companies are in one supply chain, we are called as 'green supply chain'. The coordination of supply chains - whether if traditional or green- is one of the most important research topics in this century. The number of chain members is growing; the cooperation is getting to be more difficult. That is why contracts could be a good solution for this problem, because they define a framework for the parties to manage their relationships. Contracts work well, if the right type is chosen according to the nature of the relationship. But in the case of a green supply chain, there are other influencing factors. Green companies are able to accept higher prices to get higher quality products. In the paper, we analyse how these factors influence the decision-makers to choose between the contracts; we use the AHP decision-making method.

Keywords: Green Supply Chain, Supply Chain Coordination, Decision-making, AHP

JEL classification: D21, D81, L11, L14

\section{Introduction}

These times, when the pollution of Earth is increasing constantly and the non-renewable sources are on the decrease at the same time, companies face the need of change to be sustainable and competitive. This process starts the change in business life - new manufacturing processes and techniques, new attitudes, new competencies are appeared. Companies discover the renewable sources and they have to learn how to use and handle these new things. Thus it is necessary to implement new processes into the corporate operation. One of the most popular things is the CSR - Corporate Social Responsibility. It includes every movement for the economical, ecological, and social responsibility of the sustainable operation.

Due to the technical development and also the changing attitudes some companies are getting to be eco-consciousness. It means they prefer and use processes which take into consideration 
to decrease the environmental impact. In the $21^{\text {st }}$ century companies like these are called green companies.

\section{About green supply chains}

Green companies strive to decrease the environmental impact to use eco-conscious processes within their corporate operation. This concept can extend to the whole supply chain as well. By this time the supply chain is green, so we are called green supply chain.

The concept of green supply chain is not completed, if there is a one-way chain. First, all of the chain members have to implement the eco-consciousness - integrate the environmental management to define the most important environmental factors (Beamon 1999). This helps the whole chain to be green.

As it is mentioned green supply chain is not a one-way chain, but two-way chain. It means not only the material flow is in the chain. Green companies, so green supply chain has to deal with the wastes arisen by the different processes of the chain members. Green supply chains need the inverse logistics, when the wastes are collected and, or recycled, maybe delivered to waste yard. With the help of this process wastes can be eliminated from the chain. In this case the supply chain is a closed-loop chain (Figure 1).

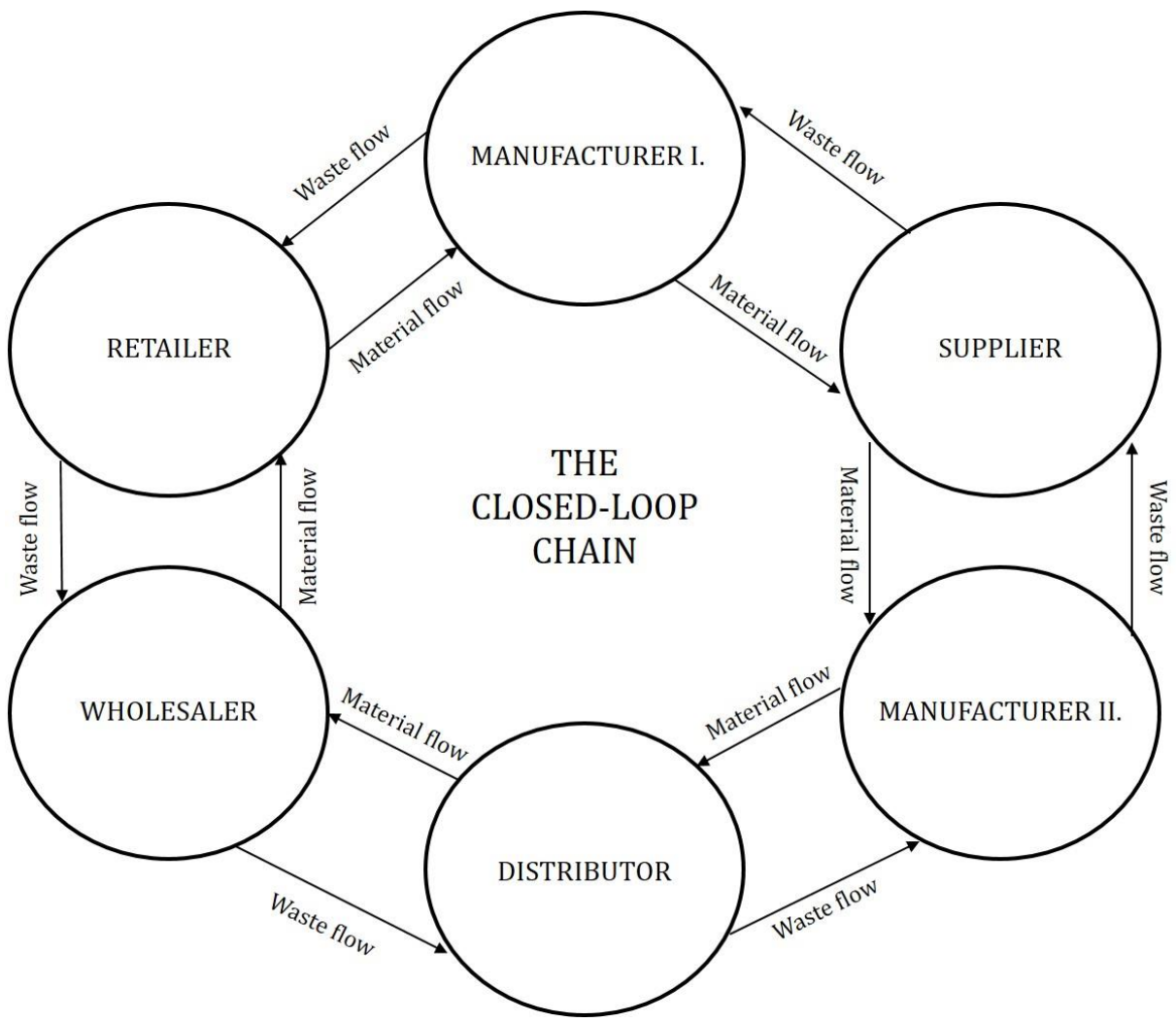

Figure 1. Example for the closed-loop supply chain (source: own construction) 
In the case of closed-loop supply chain, the recycling processes are integrated in the chain. To be more clearly, Figure 1 shows two ways of flow; first is the material flow, second is the waste flow which represents the inverse logistics or the recycling process. Here, the wastes stay inside the chain; they do not burden the environment. Chain members can earn extra profit, if the wastes can be recycled.

Nowadays, the number of the green companies and the green supply chains show an increasing tendency. More and more company take-on responsibility for the environment and implement the green concept to their corporate operation and integrate some recycling process or eco-conscious procedure into manufacturing, transporting, packaging, etc.

\section{Coordination of the chain - Contracts}

The most popular topic in the supply chain management is the coordination. There are suppliers, or manufacturers, who is the part of not just one but more supply chains. Due to the globalisation trading companies have stores or warehouses around the world. Manufacturers can choose a cheaper country to establish another factory or premises - sometimes it can be on another continent. In this case company needs to find local suppliers - and this is just one relation. Many companies can be able to have subsidiaries, other factories, and warehouses worldwide. This big network is hard to be well-coordinated. The number of the chain members is increased; the cooperation between them can be problematic. This is the reason why the supply chain coordination is an important topic.

Both of traditional and green supply chains, the efficient and profitable cooperation need a satisfactory level of coordination. If the market demand is unknown, the needs of the chain members will be unclear and this will create many problems - increasing costs, accumulated stocks will lead the company into inefficient corporate operations (Arshinder \& Deshmukh 2008). On the other hand, supply chains' biggest problem can be also appeared in this case because of the bullwhip-effect the ordered quantity is not equal with the needs, usually it is higher, therefore the stock is accumulating and it causes the increasing costs (Wang \& Disney 2016).

Thus, the information-flow is necessary to be satisfactory; the information need to be exact and precise, include every important data to the chain member. But firstly members must be willing to share the required information. In fact this is the base of a high-level cooperation. Beside that the cooperation depends on the costs and the willingness of risk-sharing.

The cooperation influenced by the members' dominance (Gelei 2003). In a supply chain members are not equal, there are bigger and stronger ones, and there are smaller and weaker ones. Usually, the stronger company is dominances the chain and the other members as well. This inequality can spoil the efficiency of the whole chain. To solve these problems supply chain management recommends to use the contracts. Contracts can decrease the level of inequality, and help to establish the higher level of cooperation. According to Coltman et al. (2009) contracts help to determine the level of risk- and benefits sharing.

There are many types of contracts; traditional ones, or some kind of newer hybrid forms. Our analysed contracts are introduced in the next chapter.

\section{Analysed contracts}

Three types of contracts are used by the paper. 
First type is the wholesale pricing. It is a traditional contract which is used frequently. Wholesaler determines the fix unit prices and there is no chance to negotiation about that. Customer pays the price and get the ordered quantity (Chakraborty et al. 2015).

Second one is the revenue-sharing contract. This type has been analysed widely by the researchers in the years of 2010 (Chakraborty et al. 2015, Krishnan et al. 2011). Its speciality is the divided retailer's profit among the chain members. This is an increasing factor of the profit of chain members.

Third is the buy-back contract. The supplier determines the buy-back price; if its partner will not able to sell all of its product, supplier will buy back the remaining products at the predetermined price (Wu 2013).

According to the literature the contracts can be potentially good solution to improve the efficiency of the coordination in the case of the supply chains.

\section{Decision specialities in case of green supply chain}

We suggest to use one of the three contracts to reach the right level of coordination which results the satisfactory cooperation. The question is which contract is the best choice?

By the green supply chain cooperation it can be more important. Produce of green products needs special proceedings, specific tools. The manufacturing or distributing process can be easily in deficit, if the appropriate information from the partner is not available - for example the market demand -, so the level of cooperation is unsatisfactory. This also leads to the deterioration of the green product's quality. However the goal of the green companies and so the green supply chain is the high quality green production. This is the only way to reduce the burden on the environment (Sarkins 2003, Gautam et al. 2019). So it is important in case of a green supply chain that the quality of the green product should be high, the cooperation between the members has a high level - maybe members can reach the full vertical integration of the chain - at the same time.

Prices of the green products are not major question. Because if a company becomes 'green' it is assumed that company is able to carry higher costs than a standard, non-green company. But the contracts include different prices as well, so this is relevant influencing factor by the choice.

With this information a complex decision situation is realised. In order to choose the right type of contract, multicriteria decision-making tool will be used.

\section{Decision method for evaluating contract types}

Choosing the appropriate type of contract is essential for the adequate cooperation. This situation contains decision points what require the application of different decision support techniques. Due to the diversity of the problem and the range of available data, it is not practical to rely on a unique best practice in different coordination decisions.

Applying multi-criteria decision-making methods is significant in every aspect of life. However, complicated procedures are less well known. Making a decision is made more difficult by the number of variants, the existence of objective and subjective criteria, inconsistencies, etc. For this reason, several decision supports methods have been developed, but one single adequate method cannot be applied in all cases; choosing the possible right 
method is influenced by many criteria, situation and the individual decision maker. MultiAttribute Utility Theory and Outranking relations are the two main lines of multi-criteria decision techniques. Applying Multi-Attribute Utility Theory means the aggregation of criteria into a function, and the examination of mathematical conditions of aggregation by maximization of the function. The compensation between criteria is allowed by the theory of method, consequently the profit of one criterion compensates for the loss of another (Pratt et al. 1976). In Outranking relation an alternative comes forward in preference order if it is at least as good as the follower while there is no essential reason to disconfirm the statement (Bouyssou, 1996). Based on the preference of the decision maker, multi-criteria decisionmaking method can be selected to determine the adequate contract type.

The process of coordination can be supported and its impact can be measured with a properly chosen method. Both qualitative and quantitative information are required for related decisions, though making a constant priority order among contract types is impossible, and for this reason a procedure is needed to manage priorities involving non-numerical correlation in the evaluation.

In this paper an Analytic Hierarchy Process (AHP) is used to analyse the contract types. The goal is to determine the importance of contract types from the perspective of decision-makers by means of hierarchization. The clarity is provided by representing the influencing factors in a hierarchical structure. The methodology and framework of AHP are described by Saaty (1987). Choosing the method is explained by the fact that it can be applied in case of both welland ill-structured problems (Forman, 1993). Reach the effective coordination level is at the top of the hierarchy, criteria $\left(\mathrm{C}_{1}-\mathrm{C}_{3}\right)$ which exert influence on the objective comes from literature as well as sub-criteria $\left(\mathrm{C}_{11}-\mathrm{C}_{32}\right)$. The structure of the decision tree is shown in Figure 2.

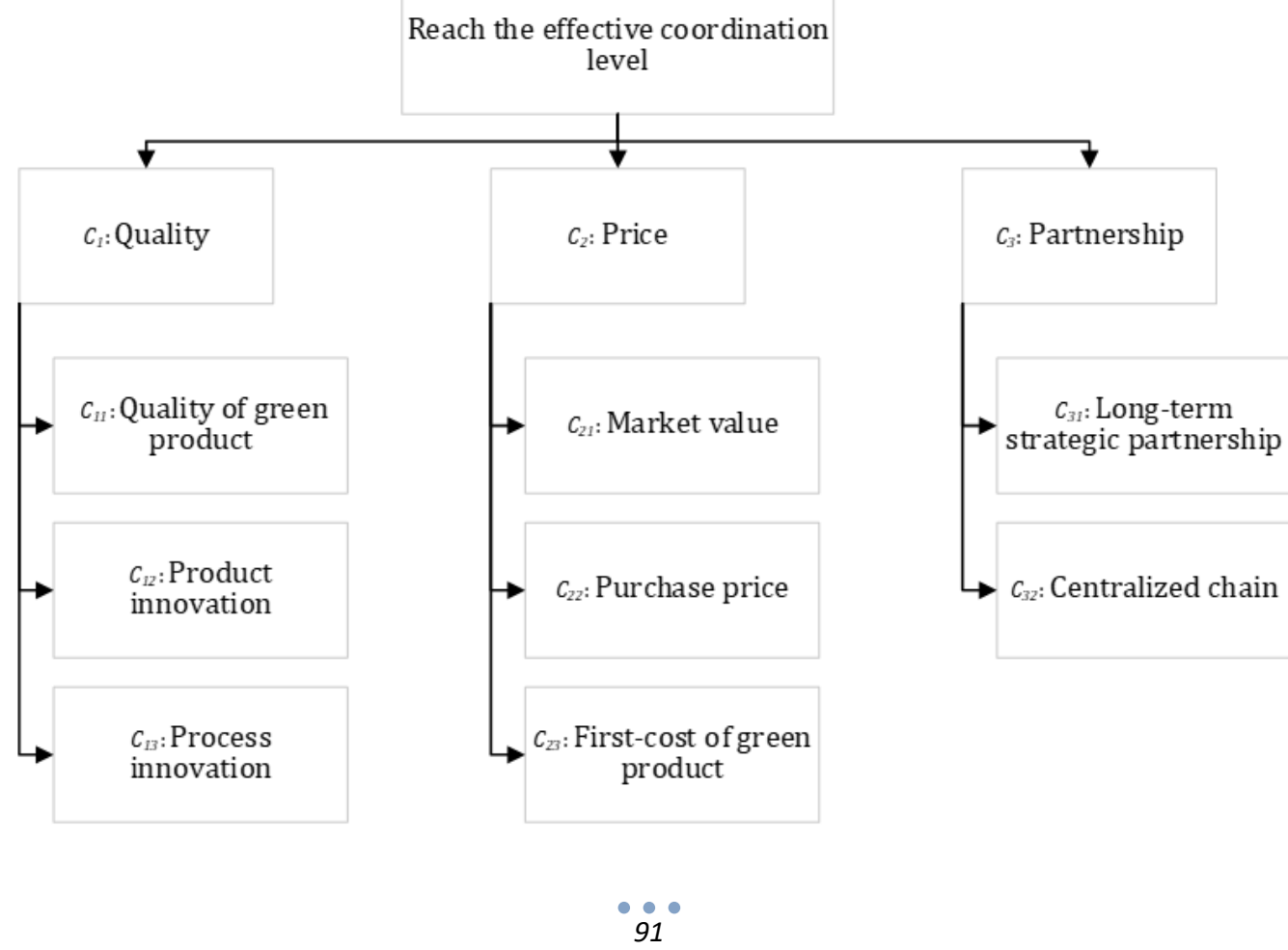



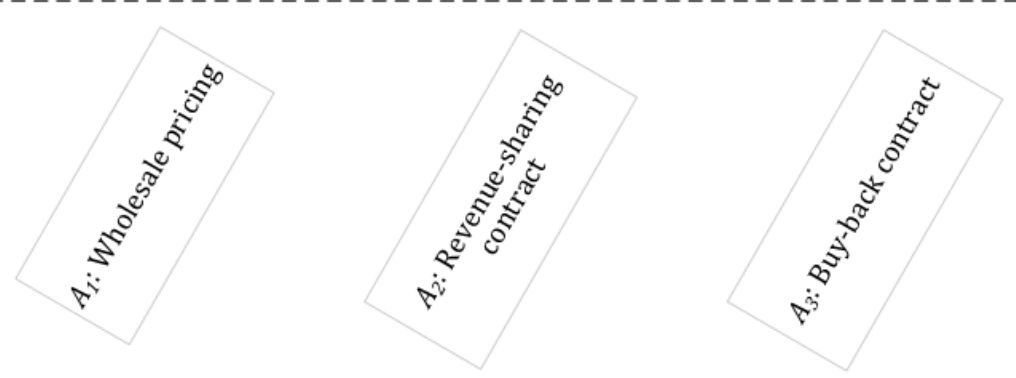

Figure 2. Decision Hierarchy (source: own construction)

Doing pairwise comparisons and calculating criteria weights are the next steps. This phase consists of three steps: determining the relative importance of the criteria by pairwise comparisons, determining weight vectors, and determining the consistency. The scale developed by Saaty (1977) provided the values 1-9 for the comparison.

The result matrix shows the relative preference of each criterion based on Formula 1.

$a_{i j}=\frac{w_{i}}{w_{j}}$,

where $a_{i j}$ is the $j$. element of matrix in line $i$. The expression is equal to the quotient of two values from a pairwise comparison, consequently it shows that criterion importance $i$ against factor $j$. The matrix is come directly from the pairwise comparisons as in Formula 2.

$\mathbf{A}=\left[\begin{array}{ccc}1 & \cdots & a_{i j} \\ \vdots & 1 & \vdots \\ \frac{1}{a_{i j}} & \cdots & 1\end{array}\right]$

The relative importance of criteria is represented by the elements of the matrix.

Determining the consistency ratio (CR) is required to measure consistency. If the value of $\mathrm{CR}$ converges to zero, the consistency is presumable.

$\mathrm{CR}=\frac{\mathrm{CI}}{\mathrm{RI}}$,

where the consistency ratio is equal to the quotient of the consistency index (CI) and the empirical average of consistency index (RI). Its value is considered satisfactory if it is not greater than 0.1. Eliminating inconsistency does not have to be the goal of decisions as it is not a sufficient condition for making good decisions. Furthermore, the value 0.1 is an empirical limit and it can be varied depending on the decision situation.

\section{Results}

The pairwise comparison have to be done by the decision maker, where the criteria are compared with the scale defined by Saaty. The matrices are constructed by the right of pairwise comparison, and the weight vectors $(\mathbf{w})$ of the alternatives $\left(A_{1}-A_{3}\right)$ are calculated from them. 
Based on the result of pairwise comparisons, the values of normalized matrices can be determined and their weight vectors can be calculated. The elements of weight vectors can be calculated with Formula 4.

$\mathbf{w}=\frac{\sum_{i=1}^{n} a_{n_{i}}}{\sum_{i, j=1}^{n} a_{n_{i j}}}$,

where the elements of weight vector $\mathbf{w}$ are defined as the quotient of aggregated sum of rows of the 7normalized matrix and sum of the elements in the whole matrix. The weight vectors for the criteria and sub-criteria are shown in Formula 5.

$\mathbf{w}_{C}=\left|\begin{array}{l}0.5 \\ 0.1 \\ 0.4\end{array}\right|$

$$
\mathbf{w}_{S C_{1}}=\left|\begin{array}{c}
0.6 \\
0.2 \\
0.2
\end{array}\right|
$$

$\mathbf{w}_{S C_{2}}=\left|\begin{array}{c}0.35 \\ 0.25 \\ 0.4\end{array}\right|$

$\mathbf{w}_{S C_{3}}=\left|\begin{array}{l}0.5 \\ 0.5\end{array}\right|$

Based on the weight vectors and the aggregated values of bottom criteria (endpoints of breakdown structure), the aggregated sums of weights $\left(\mathrm{S}\left(A_{i}\right)\right)$ can be calculated. The calculated results are shown in Table 1.

Table 2. Assessment of the alternatives (source: own calculation)

\begin{tabular}{|c|c|c|c|c|c|c|c|c|c|}
\hline \multirow{3}{*}{$A_{i}$} & $C_{11}$ & $C_{12}$ & $C_{13}$ & $C_{21}$ & $C_{22}$ & $C_{23}$ & $C_{31}$ & $C_{32}$ & \multirow{3}{*}{$S\left(A_{i}\right)$} \\
\hline & \multirow[b]{2}{*}{3} & \multirow[b]{2}{*}{5} & \multirow[b]{2}{*}{$\overline{0}$} & \multirow[b]{2}{*}{$\begin{array}{l}\text { ஜ } \\
0 \\
0\end{array}$} & \multirow[b]{2}{*}{$\begin{array}{l}\stackrel{2}{O} \\
0 \\
0\end{array}$} & \multirow[b]{2}{*}{$\begin{array}{l}\text { Z } \\
0\end{array}$} & \multirow[b]{2}{*}{$\stackrel{\sim}{0}$} & \multirow[b]{2}{*}{$\widetilde{\sim}$} & \\
\hline & & & & & & & & & \\
\hline$A_{1}$ & 0.150 & 0.400 & 0.275 & 0.550 & 0.630 & 0.730 & 0.310 & 0.850 & 0,40860 \\
\hline$A_{2}$ & 0.300 & 0.300 & 0.200 & 0.350 & 0.280 & 0.160 & 0.080 & 0.050 & 0,19175 \\
\hline$A_{3}$ & 0.550 & 0.300 & 0.525 & 0,100 & 0.090 & 0.110 & 0.610 & 0.100 & 0,39965 \\
\hline
\end{tabular}

Based on the calculation of AHP method, the preference order of the alternatives as: $A_{1}>A_{3}>$ $A_{2}$. The first alternative - wholesale pricing - can be considered the most useful in the described case.

\section{Conclusion}

Using different tools and decision support techniques is needed to explore possibilities and choose the right option. Exploring available resources and future opportunities is essential for proper evaluation. A flexibly developed decision support system is needed to support each step of the process.

Prioritizing the contract types was adequately assisted by using a ranking method based on pairwise comparisons. However, there are limitations and the preconditions should be known for proper use of these results:

The sample is not representative. 
Lack of information can affect the final rank.

The absence of mind or lack of experience of participants can provide misleading results.

The real world is often inconsistent.

Potential reluctance to use the method because of the time it takes and its heavily mathematical background.

\section{Final discussion}

Contracts can coordinate the chain, if the situation-specific one is chosen. In the case of green supply chain an important thing is the high quality green products. For this green companies are able to invest eco-conscious processes and integrate them into their corporate operation. At the same time it is a risky thing because costs are increasing but the products have not got the adequate quality. On the other hand the market demand is also needed to know because higher stock of these green products increase the inventory cost. To avoid this problem the analysed three contracts could be the solution.

If the wholesale pricing contract is used by the chain member and the cooperation level is above the average level - it means the members have the willingness to share most or all of the information and to cooperate with each other - the prices can be determined to be appropriate for both parties.

The revenue-sharing contract also helps the cooperation and also the coordination the partners and the chain. The contract has sale-incentive effect; if retailer sales more products, every chain member can realize higher profit. It assumes the information-sharing, because without it if the market demand would be unknown, sales would be decreased, stocks and the inventory costs would increase.

Buy-back contract would be motivating for retailers, customers, distributors to integrate green processes. Because according to this contract sellers, suppliers are supposed to buy the unsold products back on the predetermined buy-back price. So this is a guarantee that there will be no stocks left at the retailers or customers. And this is a motivating factor to be green company.

\section{Acknowledgements}

This research was supported by the project no. EFOP-3.6.2-16-2017-00007, titled Aspects on the development of intelligent, sustainable and inclusive society: social, technological, innovation networks in employment and digital economy. The project has been supported by the European Union, co-financed by the European Social Fund and the budget of Hungary.

\section{References}

[1] Arshinder, A., K., Deshmukh, S., G. (2008): Supply chain coordination: Perspectives, empirical studies and research directions. International Journal of Production Economics, 115, pp. 316-335. https://doi.org/10.1016/j.ijpe.2008.05.011

[1] Beamon, M. B. (1999): Designing the Green Supply Chain. Logistics Information Management, 12 (4), pp. 332-342. https://doi.org/10.1108/09576059910284159

[2] Bouyssou, D. (1996): Outranking Relations: Do They Have Special Properties? Journal of Multi-Criteria Decision Analysis, 5 (2), pp. 99-111. https://doi.org/10.1002/(sici)1099-1360(199606)5:2<99::aid-mcda97>3.0.c0;2-8 
[3] Chakraborty, T., Shauhan, S.S., Vidyarthi, N. (2015): Coordination and competition in a common retailer channel: Wholesale price versus revenue-sharing mechanisms. International Journal of Production Economics, 166, pp. 103-118. https://doi.org/10.1016/j.ijpe.2015.04.010

[4] Coltman, T., Bru, K., Perm-Ajchariyawong, N., Devinney, T. M., Benito, G.G.R. (2009): Supply Chain Contract Evolution. European Management Journal, 27 (6), pp. 388401. https://doi.org/10.1016/j.emj.2008.11.005

[5] Forman, E. H. (1993): Facts and fictions about the Analytic Hierarchy Process. Mathematical and Computer Modelling, 17 (4/5), pp. 19-26. https://doi.org/10.1016/0895-7177(93)90172-u

[6] Gautam, P., Kishore, A., Khanna, A., Jaggi, C. K. (2019): Strategic defect management for a sustainable green supply chain. Journal of Cleaner Production, 233, pp. 226-241. https://doi.org/10.1016/j.jclepro.2019.06.005

[7] Gelei, A. (2003): Az ellátási lánc típusai és menedzsmentkérdései. Vezetéstudomány, 34, pp. 24-34.

[8] Krishnan, H., Winter, R.A. (2011): On the role of revenue-sharing contracts in supply chains. Operations Research Letters, 39, pp. 28-31. https://doi.org/10.1016/j.orl.2010.10.007

[9] Pratt, J. W., Raiffa, H. Schlaifer, R. (1976): Foundations of Decision Under Uncertainty: An Elementary Exposition. Readings in Material Economics, pp. 15-30. https://doi.org/10.1016/b978-0-08-019605-3.50009-2

[10] Saaty, T. L. (1977): A scaling method for priorities in hierarchical structures. Journal of Mathematical Psychology, 15 (3), pp. 234-281. https://doi.org/10.1016/00222496(77)90033-5

[11] Saaty, R. W. (1987): The analytic hierarchy process - what it is and how it is used. Mathematical Modelling, 9 (3-5), pp. 161-176. https://doi.org/10.1016/02700255(87)90473-8

[12] Sarkins, J. (2003): A strategic decision framework for green supply chain management. Journal of Cleaner Production, 11 (4), pp. 397-409. https://doi.org/10.1016/s0959-6526(02)00062-8

[13] Wang, X., Disney, S. M. (2016): The bullwhip effect: Progress, trends and directions. European Journal of Operational Research, 250 (3), pp. 691-701. https://doi.org/10.1016/j.ejor.2015.07.022

[14] Wu, D. (2013): Coordinating of competing supply chains with news-vendor and buyback contract. International Journal of Production Economics, 144 (1), pp. 1-13. https://doi.org/10.1016/j.ijpe.2011.11.032 